\title{
Students evaluation of University teaching: Case of the clinical prosthodontics training
}

\author{
Moctar Gueye ${ }^{1, *}$, Agnes Gaëlle Kamdom Foko ${ }^{2}$, El Hadj Babacar Mbodj ${ }^{3}$, Falou Diagne ${ }^{4}$ \\ ${ }^{\mathbf{1}}$ Associate Professor, ${ }^{2}$ Part-time Dentist, ${ }^{3,4}$ Professor, Institute of Odontology and Stomatology, Cheikh Anta Diop University, \\ Dakar, Senegal
}

*Corresponding Author:

Email: makhou1@wanadoo.fr

\begin{abstract}
Introduction: Student assessment of teaching aims to identify the strengths and weaknesses of teaching. This study aimed to analyze the evaluation of the clinical prosthodontics teaching by students of the Institute of Odontology and Stomatology of the Cheikh Anta Diop University of Dakar.

Material and Methods: This was a cross-sectional descriptive study of 103 Master 1 and Master 2 students in dental surgery. The variables were related to items concerning framing, clinical teaching and assessment of clinical prosthodontics learning during the last 2 years of dental studies. Using the Likerts scale, the student had to make a quantitative assessment by assigning a score ranging from 1 to 5, depending on the degree of accreditation. The SPSS ${ }^{\circledR}$ software version 17.0 was used for statistical analysis. The comparison of averages used the Student $\mathrm{t}$ test at $5 \%$ risk of error.

Results: The majority of the sample $(79.6 \%)$ felt that the number of teachers was insufficient. Teachers were not available according to $51.4 \%$ of students. Training objectives were clearly defined for $81.5 \%$ of students. For $44.7 \%$ of them, the number of course hours was sufficient for clinical learning. Concerning the certification evaluation of learning, $66 \%$ of the students disapproved of the single final formula.

Conclusion: The practice of clinical teaching evaluation by students is an essential pillar of the overall approach to improve the prosthodontics teaching.
\end{abstract}

Keywords: Prosthodontics, Clinical teaching, Assessment, Students.

\section{Introduction}

Student Assessment of teaching aims to identify and analyse the strengths and weaknesses of an education in order to improve its quality. While evaluation provisions prevail in Canadian and American universities, where they constitute a reliable tool for assessing the quality of teaching, there is resistance in Europe to students taking ownership of the evaluation process. ${ }^{1,2}$ In sub-Saharan universities, approaches supporting the pedagogical development of teachers should be adopted along the lines of Cheikh Anta Diop University in Dakar where was initiated the process to promote performance in higher education.

The objective of this work was to analyze the students' evaluation of the clinical prosthodontics teaching in the Institute of Odontology and Stomatology (IOS) of Cheikh Anta Diop University of Dakar.

\section{Material and Methods}

This was a cross-sectional descriptive study among Master 1 and Master 2 dental students at the IOS in Dakar. The anonymity of consenting respondents has been preserved. The variables were related to sociodemographic data such as age, sex, and grade of study as well as items concerning supervision, clinical teaching and evaluation of prosthodontics clinical training during the last 2 years of dental studies. The survey was carried using a self-administered questionnaire developed from pedagogical assessment models used in other studies. ${ }^{3-5}$ A pilot survey among a random sample of 10 Master 2 students allowed to correct and readjust the questionnaire in order to facilitate understanding of the items. Using the Likerts scale ${ }^{6}$, the student had to make a quantitative assessment by assigning a score ranging from 1 to 5, depending on the degree of accreditation. The responses were organized into 3 groups:

1. Disagree for "Strongly Disagree" and "Disagree";

2. Neutral for "Neither disagree nor agree;

3. Agree for "Strongly Agree" and "Agree".

The quantitative variables were described by their means and standard deviations. The judgment made by the students on the prothodontics clinical teaching was translated into absolute and relative frequencies in an evaluation report. The statistical analysis was performed using SPSS $^{\circledR}$ software version 17.0. The structure underlying the items was evaluated by Principal Component Factorial Analysis with Varimax rotation. Items in educational areas that had a factor load greater than 0.35 were considered relevant to the evaluation of prothodontics clinical teaching. The search for the internal consistency of the items allowed to analyse the psychometric qualities of the questionnaire. The coefficient $\alpha$ of Cronbach used varies between 0 and 1 : 1 corresponded to a redundancy of items in the domain studied and 0 corresponded to a lack of consistency between items. It is all the greater as the items are correlated with each other. It must be greater than 0.6 for the internal consistency of a domain to be correct. ${ }^{6}$ 
Student's t-test compared age averages by sex. The risk of error was set at $5 \%$.

\section{Results}

Among the 120 students enrolled, 103 correctly completed the questionnaire, i.e. a response rate of $85.8 \%$. Students had an average age of $26.6 \pm 2.2$ years with a maximum of 33 years and a minimum of 23 years. Age was significantly higher for males at $27.3 \pm 1.9$ years than for females at $25.8 \pm 2.3$ years $(\mathrm{p}=0.01)$. The sample consisted of 56 men $(54.4 \%)$ and 47 women $(45.6 \%)$, i.e. a sex-ratio of 1.2 . (Table 1) There were 50 students in Master 1 and 70 in Master 2. The response rates were $68 \%$ in Master 1 and $98.6 \%$ in Master 2. Master 2 students constituted $66.9 \%$ of the sample. Girls represented $61.8 \%$ in Master 1 and $37.7 \%$ in Master 2. (Table 2)

Factor load was greater than 0.35 for all items used to evaluate the clinical teaching of prosthodontics. (Table 3) The search for internal item consistency gave the "Clinical Teaching" area a coefficient $\alpha$ of Cronbach aqual to 0.37 and an average of $3.5 \pm 0.64$. (Table 4)

Students who felt that the number of teachers was insufficient represented $79.6 \%$ of the sample. Teachers were not available during clinical sessions according to $51.4 \%$ of them. Clinical objectives were clearly defined at the beginning of teaching for $81.5 \%$ of students and assessment modalities were specified according to $41.7 \%$. For $44.7 \%$ of them, the number of class hours was sufficient for clinical training. Concerning the certificative training assessment, $66 \%$ of the students disagreed with the final single formula. (Table 5)

Table 1 : Age and gender distribution

\begin{tabular}{|c|c|c|c|c|c|}
\hline \multirow{2}{*}{ Gender } & \multicolumn{4}{|c|}{ Age (years) } & \multirow{2}{*}{$\begin{array}{c}\text { P- } \\
\text { value }\end{array}$} \\
\cline { 2 - 5 } & Mean & $\begin{array}{c}\text { Standard } \\
\text { deviation }\end{array}$ & Minimum & Maximum & \multirow{2}{*}{0.01} \\
\hline Male (n = 56) & 27.3 & 1.9 & 23 & 31 & 33 \\
\hline Female (n= 47) & 25.8 & 2.3 & 23 & 33 & \\
\hline Total & 26.6 & 2.2 & 23 & & \\
\hline
\end{tabular}

Table 2 : Distribution by gender and academic level

\begin{tabular}{|l|c|c|c|c|c|c|}
\hline \multirow{3}{*}{ Gender } & \multicolumn{3}{|c|}{ Academic level } & \multicolumn{2}{c|}{ Total } \\
\cline { 2 - 6 } & Master 1 & \multicolumn{1}{c|}{ Master 2 } & \multicolumn{2}{c|}{} \\
\cline { 2 - 6 } & $\mathrm{n}$ & $\%$ & $\mathrm{n}$ & $\%$ & $\mathrm{n}$ & $\%$ \\
\hline Male & 13 & 38.2 & 43 & 62.3 & 56 & 54.4 \\
\hline Female & 21 & 61.8 & 26 & 37.7 & 47 & 45.6 \\
\hline Total & 34 & 33.1 & 69 & 66.9 & 103 & 100 \\
\hline
\end{tabular}

Table 3 : Relevance factor analysis of evaluation items

\begin{tabular}{|l|l|c|}
\hline Pedagogical area & \multicolumn{1}{|c|}{ Items of assessment } & Factor load \\
\hline Supervising rate & The number of teachers is sufficient & 0.732 \\
\cline { 2 - 3 } & Teachers are available in clinics & 0.529 \\
\hline \multirow{3}{*}{ Clinical teaching } & Training objectives are clearly defined & 0.452 \\
\cline { 2 - 3 } & Assessment procedures are specified & 0.548 \\
\cline { 2 - 3 } & The number of course hours is satisfactory & 0.395 \\
\hline $\begin{array}{l}\text { Certificative } \\
\text { evaluation }\end{array}$ & The final evaluation is a good formula & 0.529 \\
\hline
\end{tabular}

Table 4 : Psychometric analysis of assessment areas

\begin{tabular}{|l|c|c|}
\hline \multicolumn{1}{|c|}{ Pedagogical area } & Mean \pm standard deviation & $\begin{array}{c}\text { Cronbach's } \\
\text { coefficient } \boldsymbol{\alpha}\end{array}$ \\
\hline Supervising rate & $2.28 \pm 0.41$ & 0.7 \\
\hline Clinical teaching & $3.5 \pm 0.64$ & 0.37 \\
\hline Certificative evaluation & $2.6 \pm 0.52$ & 0.56 \\
\hline
\end{tabular}

Table 5: Evaluation report on prosthodontics clinical teaching

\begin{tabular}{|l|l|c|c|c|}
\hline Pedagogical area & Clinical Evaluation Items & \multicolumn{3}{|c|}{ Assessment } \\
\cline { 3 - 5 } & & Agree & Neutral & Disagree \\
\cline { 3 - 5 } & & $\mathbf{n}(\boldsymbol{\%})$ & $\mathbf{n}(\boldsymbol{\%})$ & $\mathbf{n}(\boldsymbol{\%})$ \\
\hline Supervising rate & The number of teachers is sufficient & $11(10.7)$ & $10(9.7)$ & $82(79.6)$ \\
\hline
\end{tabular}




\begin{tabular}{|l|l|c|c|c|}
\hline & Teachers are available in clinics & $35(34)$ & $15(14.6)$ & $53(51.4)$ \\
\hline \multirow{5}{*}{ Clinical teaching } & Training objectives are clearly defined & $84(81.5)$ & $5(4.9)$ & $14(13.6)$ \\
\cline { 2 - 5 } & Assessment procedures are specified & $43(41.7)$ & $20(19.4)$ & $40(38.9)$ \\
\cline { 2 - 5 } & The number of course hours is satisfactory & $46(44.7)$ & $15(14.6)$ & $42(40.8)$ \\
\hline Certificative evaluation & The final evaluation is a good formula & $23(22.3)$ & $12(11.7)$ & $68(66)$ \\
\hline
\end{tabular}

\section{Discussion}

Given their factorial load, the items chosen to evaluate the clinical teaching of prosthodontics are relevant. ${ }^{6-8}$ However, the internal consistency of the items composing the areas corresponding to clinical teaching and certificative evaluation is low, subsequently reducing the performance of the assessment carried by the students. This needs to be addressed by improving the wording of items, the format of questionnaires or the survey process. Moreover, the use of other approaches such as documentary research, investigation among teachers and consultation of students around focus groups, can facilitate the identification of more relevant items and better internal coherence. ${ }^{6,9}$

The worldwide propensity for feminization of medical studies in general and odontological studies in particular is not confirmed by this study characterized by a predominantly male sample. This situation is due to the fact that the survey concerns students from the last two years while the other works related to students from the entire odontological cycle. ${ }^{7}$

Almost $4 / 5$ of the students consider that the ratio of clinical teaching staff is low by giving it the lowest average. This assessment seems erroneous given that the teacher/student ratio is $1: 5$ at IOS. In fact, only prosthodontics teachers participate in the clinical supervision of students and the number of supervised students can be equal to 8 for each teacher in a 4-hour shift. Thus, the availability of clinical teachers is satisfactory for only about $1 / 3$ of students. Indeed, their workload is increased by other pedagogical activities such as classroom lectures, practical instructions and direction of doctoral theses and dissertations. The recruitment of new teachers with good clinical experience in prosthodontics will ensure an overall improvement in the quality of clinical teaching.

A large majority of students stated that teachers clearly articulated the learning objectives of clinical teaching as reported by Abraham ${ }^{10}$ in a survey carried among medical students.

However, most students are divided about the amount of time allocated to the classroom lecture and the accuracy of the assessment modalities with still slightly more students approving these two items. These pedagogical provisions do not seem sufficient to enable the student to better ensure his learning and to prepare effectively for its evaluation.

The final single assessment was disapproved by almost 2/3 of the students. This assessment is justified by the nature of prosthetic treatments, which are divided into several equally important clinical and laboratory learning stages. Each of these processing steps is evaluated singly. The final single formula is therefore not a valid instrument for a rigorous and reliable process of evaluating student clinical prosthodontics training.

Given the frequent resistance to the adoption of the student assessment of teaching to evaluate "teaching performance", it seems appropriate to call on other information relays such as the teaching unit and coaching for young teachers, in order to implement a more adapted evaluation approach of teaching performance..$^{11-13}$

\section{Conclusion}

The practice of clinical teaching evaluation by students, the management of their assessments and the adoption of appropriate corrective measures are the essential pillars of the overall approach to improving, regulating and enhancing the prosthodontics teaching.

Funding: No funding sources.

Conflict of interest: None declared.

\section{References}

1. Curtis DA, Lind SL, Brear S, Finzen FC. The Correlation of Student Performance in Preclinical and Clinical Prosthodontic Assessments. J Dent Educ 2007;71(3):36572.

2. Jahangiri L, Mucciolo TW. Characteristics of Effective Classroom Teachers as Identified by Students and Professionals: A Qualitative Study. J Dent Edu 2008;72(4):484-93.

3. Davies B, Leung A, Dunne S. So how do you see our teaching? Some observations received from past and present students at the Maurice Wohl Dental Centre. Eur J Dent Educ 2006;10(4):236-41.

4. Gerekan B. Student Evaluations of Teaching Factors in Accounting Education : An Empirical Study at a Turkish University. Eur J Social Sci 2011;3(23):410-6.

5. Spoore P. On the credibility of the judge. A crossclassified multilevel analysis on students' evaluation of teaching. Stud Educ Eval 2010;36(3);121-31.

6. Joshi A, Kale S, Chandel S, Pal DK. Likert Scale: Explored and Explained. Br J Appl Sci Technol 2015;7(4):396-403.

7. Hammond SM, O'Rourke M, Kelly M, Bennett D, O'Flynn SA. Psychometric appraisal of the DREEM. BMC Med Educ 2012;12:2-5.

8. Ostapczuk MS, Hugger A, de Bruin J, Ritz S, Rotthoff T. DREEM on, dentists! Students' perceptions of the educational environment in a German dental school as measured by the Dundee Ready Education Environment Measure. Eur J Dent Educ 2012;16:67-77.

9. Nasser-Abu AF, Fresko B. Student evaluation of instruction: What can be learned from students' written comments? Stud Educ Eval 2009;35:37-44.

10. Abraham R, Ramnarayan K, Vinod P, Torke S. Students' perceptions of learning environment in an Indian medical school. BMC Med Educ 2008;(8):20-5. 
11. Anderson G. Assuring quality/resisting quality assurance: Academics' responses to "quality" in some Australian universities. Quality Higher Educ 2006;12(2):161-73.

12. Douglas J, Douglas A. Evaluating teaching quality. Quality Higher Educ 2006;12(1):3-12.

13. Smith C. Building effectiveness in teaching through targeted evaluation and response : connecting evaluation to teaching improvement in higher education. Assess and Eval Higher Educ 2008;33(5):517-33.

How to cite the article: Gueye M., Foko A., Mbodj B., Diagne F. Students evaluation of University teaching: Case of the clinical prosthodontics training. Ann Prosthodont Restor Dent 2018;4(3):72-75. 